\title{
Is the composition of exhaled breath condensate a key to explain the course of COVID-19 in children?
}

\author{
Alicja Krejner-Bienias ${ }^{1}$, Katarzyna Grzela ${ }^{1}$, Rafal Krenke ${ }^{1}$, Katarzyna Gorska ${ }^{1}$, Patrycja \\ Nejman-Gryz ${ }^{2}$, Dorota Stadnik ${ }^{3}$, Ewa Kobylska ${ }^{3}$, and TOMASZ GRZELA ${ }^{1}$ \\ ${ }^{1}$ Medical University of Warsaw \\ ${ }^{2}$ Medical Univesrity of Warsaw \\ ${ }^{3}$ Lukasiewicz Research Network - Institute of Biotechnology and Antibiotics
}

May 25, 2020

\begin{abstract}
Background: The relative resistance of children to severe course of novel coronavirus infection remains unclear. We hypothesized that there might be a link between this phenomenon and observation from our previous studies, concerning an inhibitory or cytotoxic effect of children exhaled breath condensate (EBC) on endothelial cell cultures. Since we could not find any data on similar effect caused by EBC from adults, the aim of our study was to evaluate and compare the biological activity of EBC from adults and children in an experimental in vitro model. Furthermore, in order to identify a putative agent responsible for these properties of children EBC, we attempted to analyse the composition of selected EBC samples. Methods: The influence of EBC samples on metabolic activity of endothelial cell line C-166 was assessed using colorimetric tetrazolium salt reduction assay (MTT assay). Selected EBC samples were fractionated using size exclusion chromatography and subjected to mass spectrometry analysis. Results: Exhaled breath condensates from healthy children, but not from adults, revealed a cytotoxic effect on in vitro cell cultures. This effect was most significant in condensate fraction, which contained a prominent $4.8 \mathrm{kDa}$ peak in the mass spectra. Conclusion: Breath condensates from healthy children contain the factor, which reveals inhibitory/cytotoxic effect on endothelial cell cultures. Although physiological role of this agent remains unclear, its identification may potentially be useful in ongoing research on SARS-CoV-2/COVID-19.
\end{abstract}

\section{Hosted file}

PAI-Main text.doc available at https://authorea.com/users/326176/articles/454044-is-thecomposition-of-exhaled-breath-condensate-a-key-to-explain-the-course-of-covid-19-inchildren 


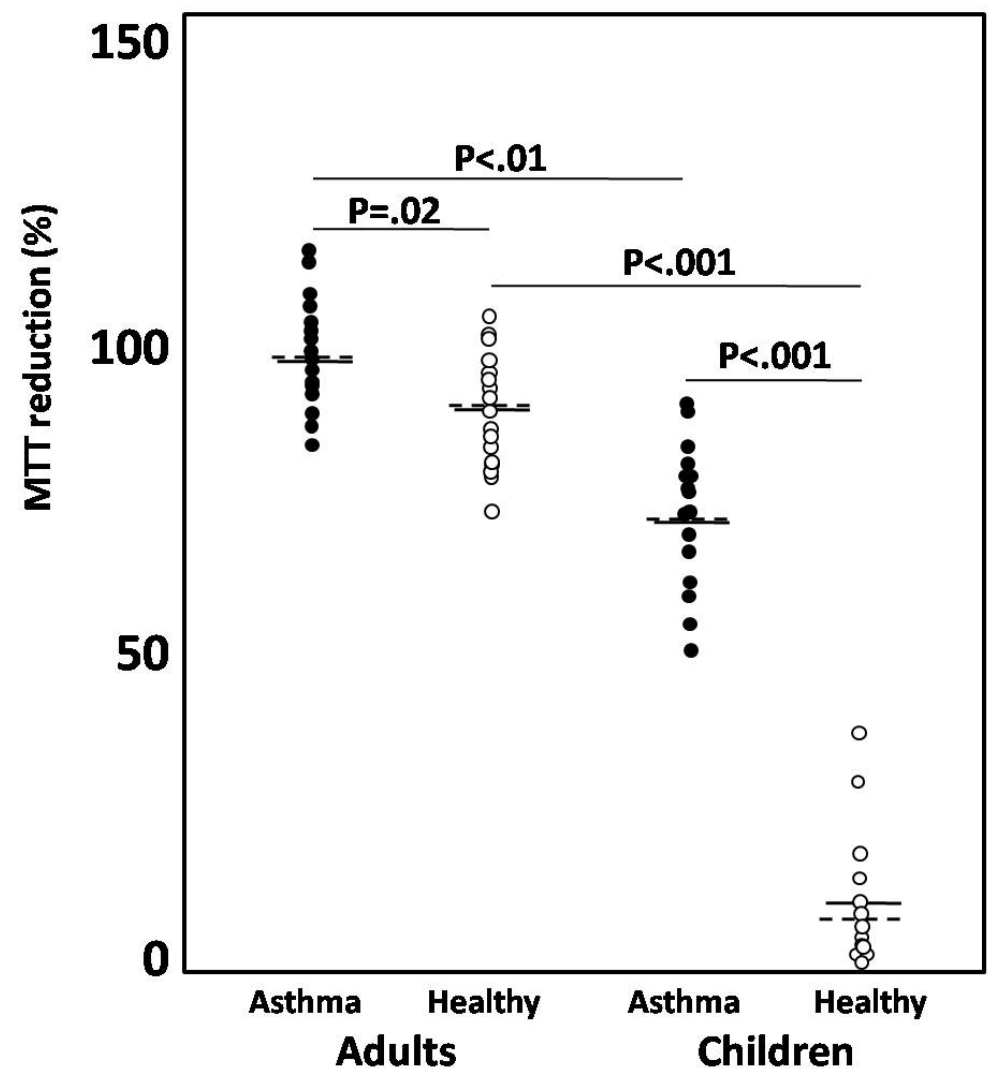




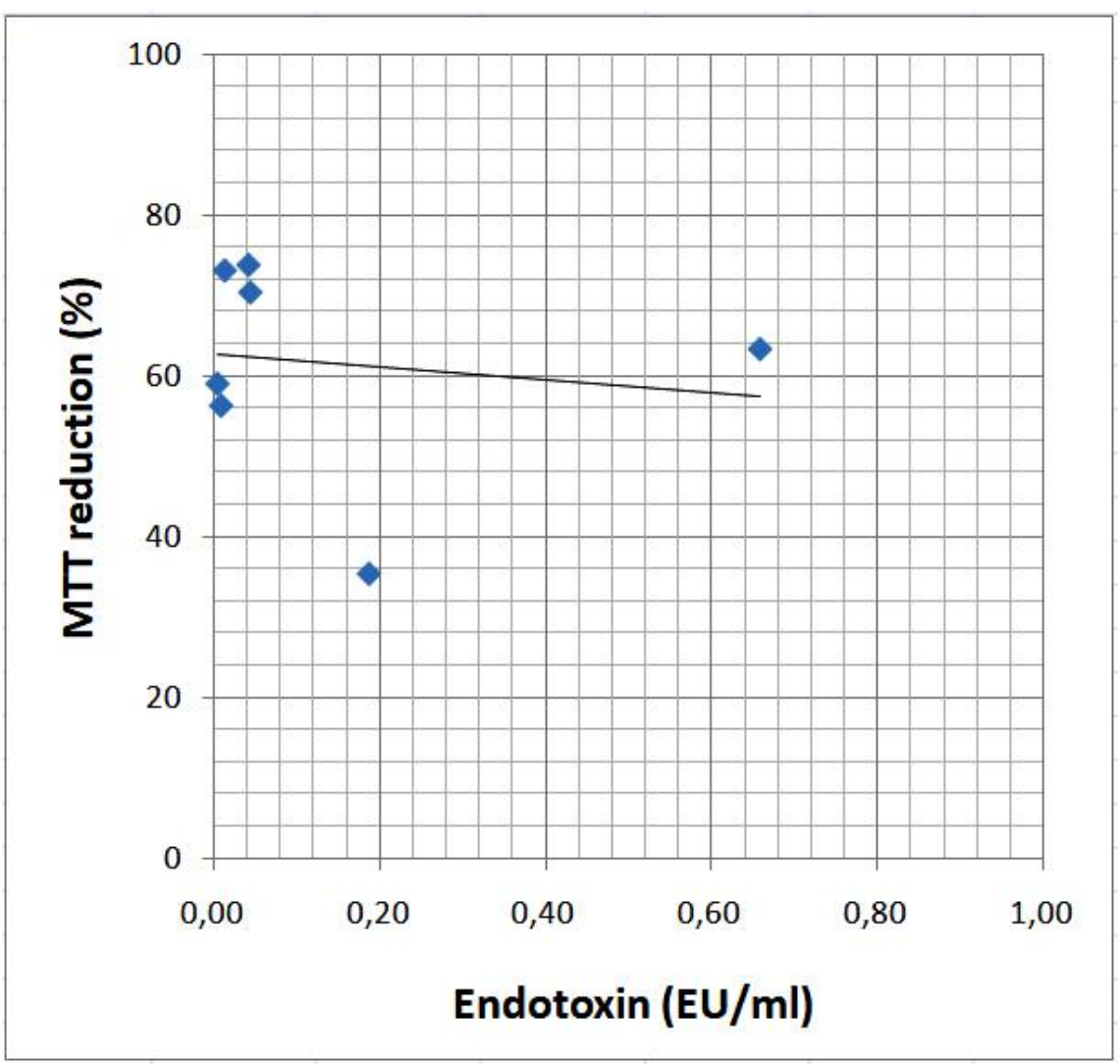




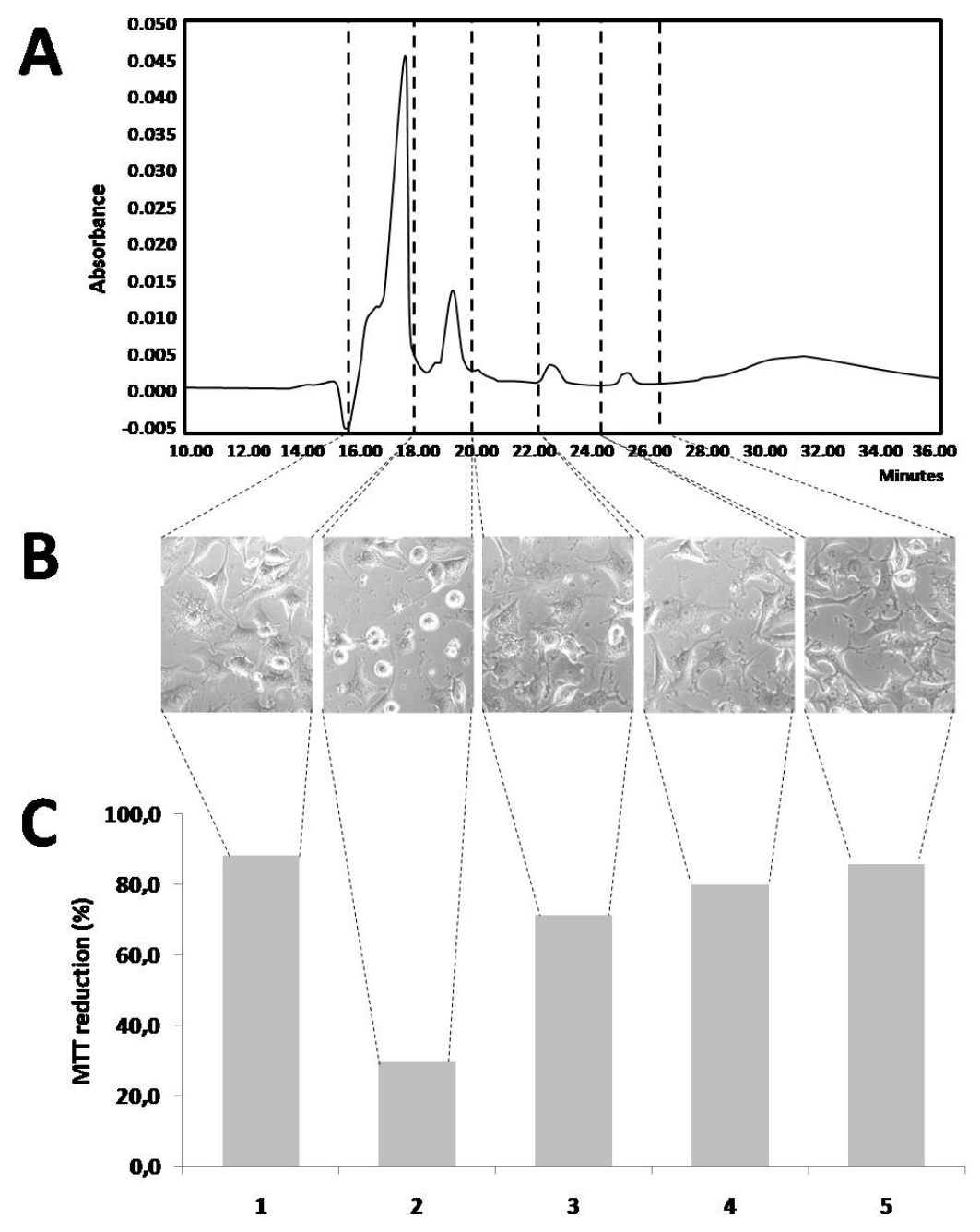




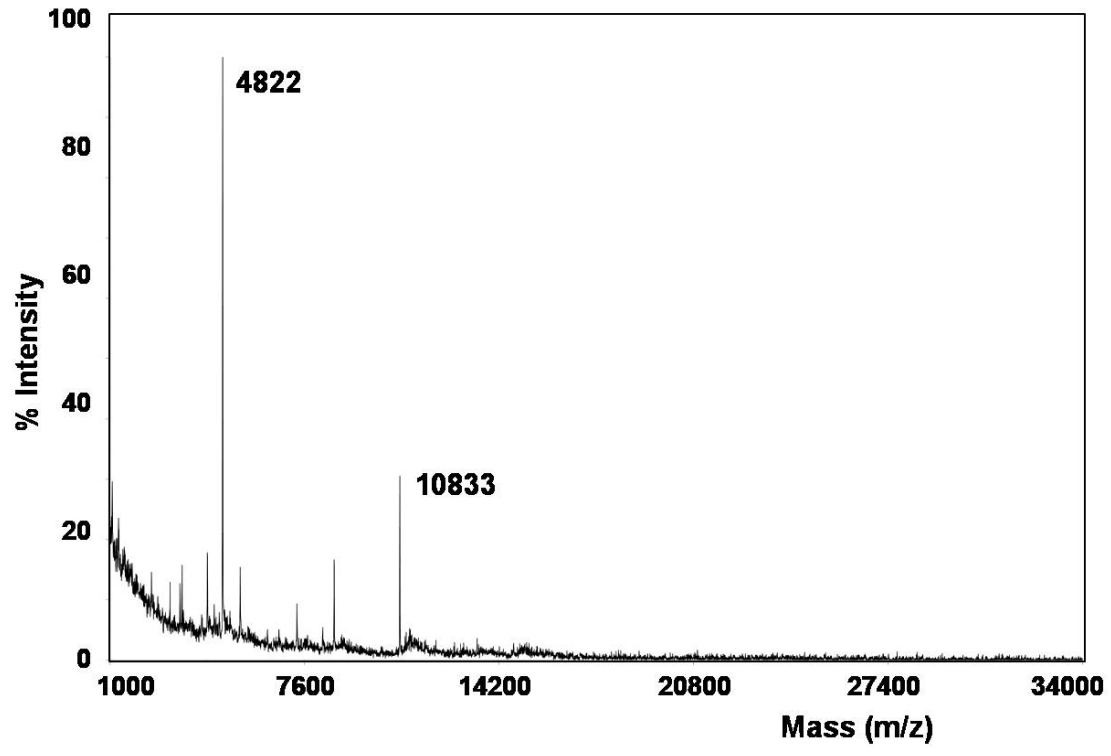

